\title{
O processo legislativo e a regulamentação do Serviço Social no Brasil: uma análise documental
}

\author{
The legislative process and the regulation of \\ Social Work in Brazil: a documentary analysis
}

\author{
Jonis Manhães Sales Felippe \\ Doutorando em Políticas Sociais pela Universidade Estadual do Norte Fluminense (Uenf), assistente social \\ do Instituto Federal Fluminense (IFF), Campos dos Goytacazes — RJ, Brasil. jonisfelippe@gmail.com
}

\begin{abstract}
Resumo: A partir de uma pesquisa documental sobre o processo que culminou na aprovação da Lei $\mathrm{n}^{\circ} 8.662 / 93$, este artigo analisa certos elementos de indefinição presentes nesse aparato legal articulando-o ao percurso legislativo. São analisados documentos produzidos pela categoria e emitidos pela Câmara e pelo Senado para compreender os efeitos de algumas perdas que se deram entre o projeto original e a lei promulgada, apontando possíveis impactos para a definição das atribuições do Serviço Social.
\end{abstract}

Palavras-chave: Atribuições privativas. Serviço Social. Legislação profissional.

\begin{abstract}
From a documentary research on the process that culminated in the approval of the Law $\mathrm{n}^{\circ} 8.662 / 93$, this article analyzes certain elements of indefinition present in the legal apparatus articulating it to the legislative process. We analyze documents produced by the category and of issued by of the Chamber and of the Senate to analyze effects some losses between the original bill and law enacted, also pointing out the impact for the definition of the and duties of the Social Work.
\end{abstract}

Keywords: Exclusive duties. Social Work. Professional legislation.

\section{Introdução}

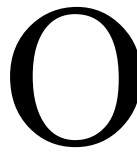

Serviço Social é uma profissão liberal regulamentada no Brasil atualmente pela Lei Federal no 8.662 de 1993, sendo uma das primeiras ocupações da área social a conquistar reconhecimento legal por parte do Estado, ainda na década de 1950, com a Lei Federal ${ }^{\circ}$ 3.252, de 27 de agosto de 1957 e o com Decreto $n^{\circ}$ 994, de 15 de maio de 
1962. Entretanto, permanecem frequentes as dúvidas (tanto entre leigos quanto entre profissionais) sobre os papéis e as funções desempenhados pelo assistente social.

Nesse sentido, é comum encontrar pessoas que acreditem na desnecessidade de formação específica para o desempenho das atividades executadas por esse profissional. Dentre essas pessoas estão usuários, profissionais de outras áreas e, de forma muito recorrente, os próprios assistentes sociais (Felippe, 2013).

Para refletir sobre um dos possíveis motivos que tem levado a essa indefinição, o presente artigo apresenta o resultado de uma pesquisa documental realizada nos Diários Oficiais do Congresso Nacional entre o final da década de 1980 e o início dos anos de 1990. Nessa direção, buscando resgatar o processo legislativo que culminou na Lei $n^{\circ} 8.662 / 93$, são analisados trechos importantes do Projeto de Lei ${ }^{0} 3.903$, de 1989, bem como os relatórios produzidos pelas comissões da Câmara e do Senado federais, as reformas produzidas no texto original e os vetos presidenciais.

Assim, pretende-se que as discussões e as indagações que emergiram da pesquisa supracitada possibilitem ao leitor visualizar que as dificuldades na delimitação das atribuições profissionais não partem somente do desconhecimento/despreparo dos profissionais, conforme já demonstrou Torres (2007), Pessanha (2010), CFESS (2012) e Felippe (2013), mas também da indefinição presente nas leis de regulamentação, algo que foi aguçado com as alterações promovidas pelos parlamentares durante o processo legislativo da atual regulamentação.

\section{A regulamentação do Serviço Social no Brasil: alguns apontamentos}

A primeira legislação a regulamentar o trabalho do profissional de Serviço Social no Brasil dizia, em seu artigo $1^{\circ}$, que "o Serviço Social constitui o objeto da profissão liberal de Assistência Social, de natureza técnico-científica" (Brasil, 1962), estabelecendo em dois dos seus artigos $\left(2^{\circ}\right.$ e $\left.5^{\circ}\right)$ as tarefas que caberiam ao assistente social, em caráter geral ou privativo. 
Essa é, na realidade, uma das principais funções das legislações profissionais - garantir pelo poder regulador do Estado o monopólio sobre a execução de determinadas atribuições e tarefas inerentes ao trabalho das profissões. Nessa direção, pode-se asseverar que o processo legislativo garante reservas de mercado ou, nas palavras de Diniz (2001, p. 65), monopólios de intervenção e prestação de serviços com base em credenciais educacionais.

Partindo-se de tais pressupostos, certos elementos e incongruências podem ser identificados já no texto de 1950, principalmente quando se avalia a previsão das atividades profissionais do assistente social. No mesmo artigo $5^{\circ}$, a Lei $\mathrm{n}^{\circ} 3.252$ de 1957 se vale das expressões "prerrogativas" e "atribuições" sem definir claramente se tais termos possuem o mesmo valor semântico. Levando-se em conta que a palavra prerrogativa refere-se a "vantagem com que se distingue pessoa ou corporação; privilégio, regalia e atribuição" (Ferreira, 1999), fica latente o entendimento de que o conjunto das tarefas listado nessa parte do texto são exclusivas do assistente social. Veja que essa concepção se difere da atual legislação de 1993, pois esta separa os artigos que tratam das atividades exclusivas e genéricas.

Art. $2^{\circ}$ São atividades profissionais do assistente social aquelas cujo exercício determina a aplicação dos processos específicos de Serviço Social.

$[\ldots]$

Art. $5^{\circ}$ São prerrogativas do assistente social:

I - Dirigir Escolas de Serviço Social;

II - Ensinar as cadeiras ou disciplinas de Serviço Social e supervisionar profissionais e alunos em trabalhos teóricos e práticos de Serviço Social;

III - Planejar e dirigir o Serviço Social, bem como executá-lo em órgão e estabelecimentos públicos autárquicos, paraestatais, de economia mista e particulares;

IV - Assessorar tecnicamente assuntos de Serviço Social nos órgãos e estabelecimentos públicos, autárquicos, paraestatais, de economia mista e particulares;

V - Realizar perícias, judiciais ou não, e elaborar pareceres sobre matéria de Serviço Social. (Brasil, 1962; grifos do autor) 
Já na primeira legislação, como se verifica, o legislador faz uso das expressões matéria, processos específicos e assuntos de Serviço Social, sem, no entanto, estabelecer com precisão o que tais termos significam. Conforme destacou Felippe (2014), o planejamento, a gestão, a assessoria e a realização de perícias e pareceres são tarefas compartilhadas por diversas categorias profissionais, as quais demandam explicitação de mais elementos para que possam se constituir como privativas do Serviço Social.

Essa legislação, que já trazia em si elementos de indefinição acerca das atribuições da profissão, permaneceu em vigor até os anos 1990, quando foi aprovada em 1993 a Lei ${ }^{\circ}$ 8.662. Contudo, o novo instrumento legal, sancionado em um período de consolidação das bases teóricas e políticas do Serviço Social pós-reconceituação, também pouco avançou na definição das atividades profissionais. Esse fato possui relação com o processo legislativo que se buscará problematizar a seguir.

A Lei no 8.662 de 1993 manteve algumas indefinições de 1957, além de ter adicionado outras imprecisões, especialmente no que se definiu como competências e como atribuições privativas nos artigos $4^{\circ}$ e $5^{\circ}$. Segundo parecer jurídico elaborado por Terra (1998) a pedido do CFESS, as competências e as atribuições estão em artigos diferentes porque o legislador pretendeu diferenciar o significado desses termos. Para Terra (1998) e Iamamoto (2012), o artigo $4^{\circ}$ (competências) descreve atividades possíveis de serem executadas por assistentes sociais e por outros profissionais, sendo, desse modo, genéricas. Por outro lado, o artigo $5^{\circ}$ (atribuições privativas) enumera uma série de ações reservada aos assistentes sociais.

Destaca-se, nessa linha de raciocínio, a representatividade do inciso XI do artigo $4^{\circ}$, transcrito a seguir: "realizar estudos socioeconômicos com os usuários para fins de benefícios e serviços sociais junto a órgãos da administração pública direta e indireta, empresas privadas e outras entidades" (Brasil, 1993). Tal atribuição, executada por profissionais de Serviço Social em diversas instituições, aparece descrita como competência, o que permitiria legalmente a sua execução por outros profissionais. Acontece o mesmo no inciso III também do artigo $4^{\circ}$, em que a ação de "encaminhar providências, 
e prestar orientação social a indivíduos, grupos e à população" (Brasil, 1993) é descrita como competência.

Apesar do parecer de Terra (1998) e do texto de Iamamoto (2012) identificarem esses equívocos e afirmarem que tais tarefas devem ser compreendidas como atribuições privativas pelos assistentes sociais, tais posicionamentos não possuem força legal para impedir que outros profissionais se habilitem para executá-las. Legalmente falando, apenas as tarefas abaixo estão asseguradas como "monopólios" (Diniz, 2001) ou prerrogativas exclusivas dos assistentes sociais:

Art. $5^{\circ}$ Constituem atribuições privativas do assistente social:

I - coordenar, elaborar, executar, supervisionar e avaliar estudos, pesquisas, planos, programas e projetos na área de Serviço Social;

II - planejar, organizar e administrar programas e projetos em unidade de Serviço Social;

III - assessoria e consultoria e órgãos da administração pública direta e indireta, empresas privadas e outras entidades, em matéria de Serviço Social; IV - realizar vistorias, perícias técnicas, laudos periciais, informações e pareceres sobre a matéria de Serviço Social;

V - assumir, no magistério de Serviço Social tanto a nível de graduação como pós-graduação, disciplinas e funções que exijam conhecimentos próprios e adquiridos em curso de formação regular;

VI - treinamento, avaliação e supervisão direta de estagiários de Serviço Social;

VII - dirigir e coordenar unidades de ensino e cursos de Serviço Social, de graduação e pós-graduação;

VIII - dirigir e coordenar associações, núcleos, centros de estudo e de pesquisa em Serviço Social;

IX - elaborar provas, presidir e compor bancas de exames e comissões julgadoras de concursos ou outras formas de seleção para assistentes sociais, ou onde sejam aferidos conhecimentos inerentes ao Serviço Social; $\mathrm{X}$ - coordenar seminários, encontros, congressos e eventos assemelhados sobre assuntos de Serviço Social; 
XI - fiscalizar o exercício profissional através dos Conselhos Federal e Regionais;

XII — dirigir serviços técnicos de Serviço Social em entidades públicas ou privadas;

XIII - ocupar cargos e funções de direção e fiscalização da gestão financeira em órgãos e entidades representativas da categoria profissional. (Brasil, 1993; grifos do autor)

Como se percebe, essas tarefas compõem o leque do que se regulamentou como monopólios de prestação de serviço ou prerrogativas exclusivas do Serviço Social. Contudo, fica evidente que os termos capazes de diferenciar as atribuições genéricas (tais como administração, assessoria, planejamento, realização de perícias e laudos, entre outras) das que possuem caráter privativo permanecem inespecificados, mantendo a estrutura da legislação de 1957. É o caso dos incisos I, II, III, IV e XII, os quais utilizam as expressões matéria, área, unidade e serviços técnicos de Serviço Social.

A análise do art. $5^{\circ}$ relativo às atribuições privativas do assistente social, especialmente os incisos de I a IV, indica que a maior dificuldade na identificação desse caráter privativo não se encontra na descrição ou relato da atividade a ser desenvolvida, que em si mesma não é prerrogativa de qualquer profissional em particular, como, por exemplo: coordenar, elaborar, executar, supervisionar e avaliar estudos, pesquisas e projetos; planejar, organizar e administrar projetos; realizar assessoria e consultoria a órgãos da administração pública direta e indireta, empresas privadas e outras entidades; realizar vistorias, perícias técnicas, laudos periciais, informações e pareceres. O que delimita o caráter da atividade enquanto privativa do assistente social é a sua qualificação enquanto matéria, área e unidade de Serviço Social. (Iamamoto, 2012, p. 38)

O parecer de Terra (1998) também elenca outras incongruências, registradas no artigo $4^{\circ}$ (competências). De acordo com a assessora, os incisos II $^{1}$

1. "Elaborar, coordenar, executar e avaliar planos, programas e projetos que sejam do âmbito de atuação do Serviço Social com participação da sociedade civil" (Brasil, 1993). 
e VIII ${ }^{2}$ são repetidos nos incisos I e III do artigo $5^{\circ}$, o que pode gerar dúvidas no entendimento acerca do seu caráter privativo ou não. Uma atribuição profissional não pode, necessariamente, se configurar atividade genérica e exclusiva ao mesmo tempo, uma vez que caráter privativo configura-se justamente pelo impedimento da sua execução por leigos ou outras ocupações.

O texto traz ainda outras definições, como a fiscalização do exercício, a supervisão de estágio de estudantes, a elaboração de avaliações para assistentes sociais e funções acadêmicas que digam respeito ao Serviço Social. Todas elas descritas no artigo $5^{\circ}$, sem prejuízos aos assistentes sociais por se direcionarem especificamente para a formação ou controle entre os pares, características básicas do processo de profissionalização segundo Coelho (1998).

Embora possa parecer uma questão apenas de forma jurídica, essas indefinições no aparato legal da categoria vêm contribuindo para diversas confusões acerca do papel e das atividades inerentes ao trabalho do assistente social. No próprio texto elaborado pelo CFESS (2012), constata-se, com base nos registros das Comissões de Orientação e Fiscalização (Cofis) dos CRESS, que os agentes de fiscalização relatam muitas dificuldades para averiguar, identificar e distinguir as competências e atribuições privativas dos assistentes sociais (CFESS, 2012, p. 23), conforme descrições abaixo:

- Falta objetividade no que diz respeito à especificação das atribuições do(a) assistente social.

- Não uniformização quanto à atuação do(a) assistente social por área.

- Compreender nos incisos I, III, IV do art. 5, o que se constitui área e matéria do Serviço Social.

- Atividades desenvolvidas por assistentes sociais estão mais relacionadas ao art. 4, dificultando a aplicabilidade da lei, na qualificação do exercício ilegal.

- Há ambiguidade/repetição dos incisos II, VIII, X do art. 4 com os incisos I, II, III do art. 5.

2. "Prestar assessoria e consultoria a órgãos de administração pública direta e indireta, empresas privadas e outras entidades, com relação às matérias relacionadas no inciso II deste artigo" (Brasil, 1993). 
- Desconhecimento dos(as) profissionais da Lei no 8.662/93 e do Código de Ética e falta de acompanhamento do processo de formação, especialmente das escolas particulares.

- Atividades historicamente assumidas por assistentes sociais não estão caracterizadas no art. $5^{\circ}$ [...]. (CFESS, 2012, p. 25-26).

Sobre esse assunto, também chama a atenção as dificuldades identificadas entre os próprios assistentes sociais em diferenciar princípios, deveres éticos, tarefas genéricas ou exclusivas e direitos, algo já relatado nas pesquisas de Torres (2007), Pessanha (2010), CFESS (2012) e Felippe (2013). Nessa perspectiva, considerando que muitas dessas indefinições emergem da própria legislação do Serviço Social no Brasil, buscar-se-á demonstrar, por meio da análise documental, cujos resultados serão expostos nos itens a seguir, como o processo legislativo que culminou na atual lei de regulamentação profissional (8.662 de 1993) pode ter contribuído significativamente para essa imprecisão.

\section{A apresentação do projeto de Lei n 0.903 de 1989}

A atual Lei ${ }^{\circ} 8.662$ de 1993 é fruto de um longo processo legislativo iniciado com o Projeto de lei n. 3.903 de 1989 de autoria das deputadas federais Benedita da Silva (PT) e Maria de Lourdes Abadia (PSDB). Inicialmente, a proposta apresentava um conjunto de 28 artigos, que foram reduzidos a 24 após as alterações promovidas pelo Congresso Nacional e, posteriormente, a 23, com o veto presidencial do artigo 21 antes da sua promulgação em junho de 1993.

Embora esse assunto não tenha sido abordado em produções acadêmicas de destaque no interior da profissão, as alterações promovidas certamente materializaram um conjunto de perdas significativas para a categoria. No projeto inicial constavam vários itens que, se aprovados, teriam fortalecido tanto o exercício profissional quanto a fiscalização por parte do CFESS e do CRESS. 
Os fundamentos apresentados pelas autoras do projeto para a aprovação de uma nova regulamentação do Serviço Social no Brasil, concatenada com os avanços acadêmicos e com a reconceituação da profissão no país, se baseiam na existência de novas competências e atribuições construídas no seio das profundas transformações sociais ocorridas desde a última lei de 1957. Nessa perspectiva, certamente a construção do aludido projeto, cuja justificativa encontra-se transcrita em parte abaixo, contou com a assessoria e o aval das entidades representativas da profissão. Afinal, foi discutido e aprovado no XVII Encontro CFAS/CRAS de 1989 (Almeida, 2006).

Nos anos 60, a profissão passa por profundas críticas, expressando-se tanto na vertente modernizadora modelada nos marcos do desenvolvimentismo nos quais se reforça o perfil tradicional da profissão, como na vertente crítica que identificará o significado social da profissão nas lutas pela igualdade de direitos e pela superação da pobreza e da exploração humana peculiares à sociedade brasileira, indicando as possibilidades objetivas da profissão se posicionar no horizonte dos interesses dos trabalhadores.

[...] É nesse contexto da prática profissional que emerge da categoria uma reivindicação no sentido de amparar legalmente suas novas atribuições e competências, fruto dos avanços realizados pela profissão, dando uma nova qualidade à prática. (Brasil, 1989, p. 12.693)

Nesse sentido, buscando diferenciar-se da legislação de 1957, que possuía apenas sete incisos em seu artigo $5^{\circ}$ dedicados a estabelecer tarefas pertinentes à profissão, o projeto $\mathrm{n}^{\mathrm{o}} 3.903$ de outubro de 1989 elencava um conjunto de 25 incisos, distribuídos entre os artigos $5^{\circ}$ e $6^{\circ}$ (posteriormente transformados em $4^{\circ}$ e $5^{\circ}$ na Lei $\mathrm{n}^{\circ} 8.662 / 93$ ), que se propunham a definir as atividades pertencentes ao campo de atuação do assistente social. Pelo menos quantitativamente, o projeto inicial sinaliza um grande aumento nas possibilidades de atuação, contemplando, entre as competências profissionais, funções de planejamento e administração de políticas sociais, bem como atividades de pesquisa, assessoria e consultoria.

$\mathrm{O}$ aludido projeto, com vistas à aprovação na Câmara de Deputados Federais, foi submetido, nesse primeiro momento, à apreciação de duas 
comissões parlamentares - Comissão de Constituição e Justiça e de Redação (em junho de 1990) e Comissão de Trabalho, de Administração e Serviço Público (em novembro de 1990) (Brasil, 1990). Nos dois espaços, a iniciativa das deputadas autoras foi reconhecida pelos relatores, os quais promoveram pouquíssimas mudanças no texto original. Cabe destacar que, decorridos os prazos estabelecidos pelas comissões, nenhum deputado apresentou emendas ao documento original antes da apreciação do relator.

Não obstante, o relator da Comissão de Constituição e Justiça e Redação, deputado Messias Góis (PFL), respaldando-se na necessidade de aprimoramento da técnica legislativa, propôs a modificação da ementa do projeto e a exclusão do artigo $4^{\circ}$, por considerar desnecessária a sua redação. Inicialmente, o texto previa o seguinte na ementa e no artigo $4^{\circ}$, respectivamente:

Revoga a Lei n. 3.252, de 27 de agosto de 1957 e dispõe sobre a regulamentação da profissão de assistente social.

[...] Art. $4^{\circ}$ A profissão de assistente social será exercida:

I - mediante contrato de trabalho regido pela Consolidação das Leis do Trabalho (CLT);

II - em regime estatutário no âmbito federal, estadual e municipal, de acordo com a legislação em vigor;

III — de forma autônoma. (Brasil, 1990, p. 13.335)

A ementa foi substituída pela frase "Dispõe sobre a profissão de assistente social e dá outras providências". Por outro lado, os demais artigos foram renumerados com a exclusão do artigo $4^{\circ}$, o que possivelmente não trouxe limitações ou perdas significativas para a profissão, especialmente no que tange à definição de suas atribuições. Destaca-se, porém, que muitas das decisões judiciais que se manifestaram contrariamente à aplicação da Lei $\mathrm{n}^{\mathrm{o}} 12.317$ de 2010 (redução da carga horária para trinta horas) aos assistentes sociais que atuam em regime estatutário se justificaram na ausência de contrato de trabalho nesse tipo de vínculo. A manutenção desse artigo poderia ter influenciado na redação texto de 2010 , evitando que apenas o inciso I fosse contemplado pela legislação atual. Entretanto, essas são suposições 
impossíveis de ser confirmadas após tantos anos entre a apresentação do projeto e a conquista das trinta horas.

Um ponto que chama a atenção nos documentos emitidos pelos deputados responsáveis é o reconhecimento da contribuição dos assistentes sociais no processo de construção e efetivação das políticas sociais no país, o que justificou a emissão de pareceres favoráveis nos relatórios da Comissão de Constituição e Justiça e de Redação e da Comissão de Trabalho, de Administração e Serviço Públicos. Os dois espaços de discussão e análise do projeto foram concordes ao apontar para a necessidade e constitucionalidade do mesmo. As grandes perdas, porém, começam a se concretizar quando o projeto, após aprovação na Câmara de Deputados Federais, é encaminhado para o Senado Federal, que promove uma mudança crucial nos artigos definidores das competências e atribuições privativas. Além disso, importantes trechos do texto são excluídos, em especial os artigos que garantiam a presença de assistentes sociais em certas instituições prestadoras de serviços sociais.

\section{As mudanças promovidas durante o processo legislativo acerca das competências e atribuições privativas do assistente social}

No que concerne às atribuições e às competências profissionais, a grande modificação promovida foi a retirada do inciso II do artigo $5^{\circ}$ e a sua inclusão no artigo $4^{\circ}$ como inciso XI. Desse modo, a realização de estudos socioeconômicos para fins de benefícios e serviços sociais deixou de ser uma possível tarefa exclusiva da categoria dos assistentes sociais para se tornar uma competência, consequentemente aberta para a execução por outros profissionais. Também foi eliminado o inciso III do mesmo artigo $5^{\circ}$, o qual previa como privativa dos assistentes sociais a ocupação de "cargos efetivos ou em comissão, funções de assessoria técnica, consultiva, direção, chefia, supervisão e execução em entidades públicas ou privadas cujas atribuições sejam pertinentes ao Serviço Social”' (Brasil, 1992a, p. 3.408).

É interessante notar que em nenhum dos documentos que estão disponíveis para acesso no Diário do Congresso Nacional existe uma justificativa 
para a passagem do inciso sobre estudos socioeconômicos para o âmbito das competências. Ao contrário disso, essa modificação passa "quase que despercebida" entre relatores e presidentes de comissões, que não chegam nem a listá-la como uma mudança substancial num relatório emitido em 12 de novembro de 1992 (Brasil, 1992b, p. 27.790). Já a retirada do inciso III do artigo $5^{\circ}$ é fundamentada no argumento de que a ocupação de cargos efetivos ou em comissão (envolvendo atividades de chefia, direção, supervisão e assessoria com atribuições "pertinentes ao Serviço Social") exige formação técnica compatível (visão política, conhecimento sobre administração pública e privada), o que muitas vezes não é encontrado num assistente social (Brasil, 1992b, p. 27.789).

Além disso, outro relatório - emitido pela Comissão de Trabalho, de Administração e Serviço Público da Câmara de Deputados em outubro de 1992 - informa que a aprovação do dispositivo anterior (inciso III) levaria à desmontagem de toda uma estrutura de serviços como Sesi (Serviço Social da Indústria) e Sesc (Serviço Social do Comércio) por querer tornar privativa do assistente social as funções comissionadas e de chefia relatadas. Importa destacar que os novos relatórios e pareceres das Comissões da Câmara de Deputados (com conteúdo claramente contrário aos que foram elaborados para o projeto original da mesma casa) só foram construídos após essas e outras modificações fornecidas pelo Senado Federal, as quais deram origem a um projeto substitutivo que contemplou também a exclusão de itens que serão analisados a seguir.

No projeto original constava, por exemplo, como atribuição dos CRESS, em suas respectivas jurisdições, a função de disciplinamento, fiscalização e normatização das ações desenvolvidas por entidades (pessoas jurídicas) de direito público ou privado que tivessem as atividades ligadas ao Serviço Social como seu objeto. Essa tarefa estava descrita no artigo 10, inciso VIII, porém foi eliminada com base na seguinte justificativa:

O inciso VIII do artigo 10, que outorga aos Conselhos Regionais de Serviço Social a prerrogativa de "disciplinar, fiscalizar e normatizar" as atividades de pessoas jurídicas, públicas e privadas, que tenham por objeto preponderante 
atividades ligadas ao Serviço Social constitui-se num flagrante atropelo à liberdade de iniciativa e no estabelecimento de um vínculo de subordinação inadmissível. Todos os serviços e entidades voltados para a assistência social passariam, na verdade, a ser geridos pelos Conselhos Regionais de Serviço Social, numa flagrante deturpação das funções institucionais destes. (Brasil, 1992b, p. 27.789)

Como fica perceptível, existe uma clara redução da área de Serviço Social às atividades de assistência social, o que de certa forma fundamenta o parecer negativo do relator. Por outro lado, cabe destacar o fato de que os conselhos profissionais são autarquias, ou seja, personalidades jurídicas de direito público, pertencentes ao campo da administração indireta, que possuem a função de executar atividades típicas do Estado. No caso em questão, as atividades envolvem a organização, a manutenção e a execução da "inspeção do trabalho", conforme estabelece a Constituição Federal de 1988 em seu artigo 21, inciso XXIV. Em outras palavras, a criação dos conselhos de categoria, por meio das leis de regulamentação das profissões, visa assegurar a intervenção do Estado nas atividades desenvolvidas pelas profissões, garantindo o controle social das mesmas, de maneira a prevenir que suas atuações sirvam a interesses clientelísticos ou pessoais (Simões, 2009, p. 407).

Como se vê, entendeu-se que não existiria justificativa legal para garantir aos CRESS a competência própria de fiscalizar, disciplinar e, especialmente, normatizar as ações de pessoas jurídicas, mas somente as condições de trabalho e as atividades dos assistentes sociais trabalhadores dessas instituições. No entanto, embora não estejam diretamente subordinadas à normatização elaborada pelos conselhos profissionais, as empresas e entidades estão sujeitas ao atendimento dos requisitos estabelecidos pelas legislações profissionais construídas pelo próprio Estado, as quais garantem as prerrogativas, os requisitos e os elementos básicos para o exercício das funções previstas para a profissão. Para que não restem dúvidas, basta consultar novamente a Constituição Federal de 1988 em seu artigo 22, inciso XI, que estabelece como competência privativa da União legislar sobre 
“organização do sistema nacional de emprego e condições para o exercício das profissões" (Brasil, 1988).

Se essa leitura estivesse presente na abordagem adotada pelos relatores do Senado Federal, ou mesmo se tais argumentos tivessem sido apresentados como recurso nas comissões que promoveram as alterações no projeto original, os artigos 14, 15 e 16 do texto enviado pela Câmara ao Senado não teriam sido excluídos, conforme se verifica adiante. O projeto em questão contava com a seguinte redação:

Art. 14 - As sociedades organizadas e as que se organizarem para a prestação de serviços profissionais em quaisquer das atribuições definidas no art. $4^{\circ}$ desta lei só poderão ser constituídas se na sua composição houver assistente social como responsável técnico, devidamente inscrito no Conselho Regional de Serviço Social e que esteja, junto a este, em pleno gozo de seus direitos profissionais.

$\S 1^{\circ}$ - Os assistentes sociais que integram as sociedades de que trata este artigo responderão individualmente perante os Conselhos Federal e Regionais sobre assuntos atinentes a suas atividades específicas.

$\S 2^{\circ}$ - Os assistentes sociais que participarem das sociedades previstas neste artigo, uma vez suspensos do exercício da profissão, por decisão do Conselho Federal ou dos Regionais, não poderão praticar ato profissional a serviço ou em nome da sociedade enquanto perdurar a punição.

$\S 3^{\circ}$ - Qualquer alteração estatutária ou contratual ocorrida nas sociedades de que trata este artigo deverá, obrigatoriamente, ser comunicada ao Conselho Regional competente, no prazo de até 30 (trinta) dias, a partir da data de sua ocorrência.

Art. 15 - As instituições e obras sociais públicas e privadas, ou de fins filantrópicos, as organizadas e as que se organizarem com as atribuições constantes do inciso III do art. $5^{\circ}$ desta lei, quaisquer que sejam suas denominações ou natureza jurídica, só poderão funcionar se contarem com assistente social devidamente registrado no Conselho Regional de sua área de jurisdição e que esteja em pleno gozo de todos os seus direitos profissionais.

Art. 16 - As organizações constantes dos arts. 14 e 15 desta lei serão obrigatoriamente inscritas nos Conselhos Regionais de Serviço Social de suas 
respectivas jurisdições, para que possam praticar quaisquer atos de natureza profissional, sujeitando-se também ao pagamento das contribuições compulsórias (anuidades), taxas e emolumentos que forem estabelecidos em resoluções baixadas pelo Conselho Federal. (Brasil, 1992a, p. 3408).

A exclusão desses três importantes artigos materializou um conjunto de perdas importantes para os assistentes sociais no Brasil, bem como comprometeu a obrigatoriedade de que determinados projetos, programas, serviços e benefícios sociais tivessem em seu quadro pessoal um profissional habilitado e devidamente treinado para a sua elaboração, execução e avaliação. Se se recorre às contribuições oferecidas por Freidson (1998), seria pertinente constatar que a inviabilização da presença obrigatória do assistente social, nas instituições que oferecem serviços previstos nos artigos que tratam das competências e atribuições privativas do Serviço Social, demonstra a consonância do legislador em manter esse conjunto de ações no campo do "amadorismo".

Não obstante, essa situação aponta para a fragilidade dos mecanismos de credenciamento do Serviço Social, demonstrando o não reconhecimento legal dos conhecimentos e competências especializados da profissão (expertise) na realização de determinado trabalho. Tal fato fica ainda mais evidente ao se analisar a justificativa do relator que emitiu parecer negativo para a manutenção dos aludidos artigos. Na sua concepção, o projeto objetivava “uma verdadeira e indisfarçável 'reserva de mercado', mediante a outorga de privilégios a um reduzido número de pessoas, em detrimento de toda a sociedade" (Brasil, 1992b, p. 27.789).

Os argumentos desfavoráveis prosseguem apontando que a aprovação do texto inicialmente apresentado pela Câmara de Deputados Federais apresenta-se como um "atropelo à liberdade de iniciativa", capaz de promover o desestímulo às instituições e obras sociais. Na realidade, o recurso aos autores do campo da sociologia das profissões permite evidenciar que a imposição da necessidade de contratação de assistentes sociais pelas instituições, para a prestação dos serviços listados antes, realmente configura um mecanismo de abrigo ou controle de mercado de serviços (Freidson, 1998), embora não 
tenha um caráter injustificado. O controle sobre um mercado de prestação de serviços é um dos elementos mais importantes presentes na análise histórica do processo de profissionalização das ocupações no Brasil e em outros países do mundo (Coelho, 1998).

Seguindo a linha de abordagem adotada por Larson (1977), pode-se compreender que o Serviço Social não logrou êxito no seu processo de $f e$ chamento social na atual regulamentação, ou seja, na criação de mecanismos legais que permitissem a restrição aos leigos no acesso a certos recursos e oportunidades relacionados ao campo de atuação profissional. Para Coelho (1998), um dos pontos principais a serem atendidos pelas profissões que aspiram ao reconhecimento legal de suas tarefas por parte do Estado é a articulação com membros do Legislativo que se proponham não apenas a apresentar um projeto de lei, mas a zelar pelo seu percurso até a aprovação.

Certamente, essa articulação só é possível se determinados setores do Estado e da sociedade estiverem convencidos de que a qualidade na prestação dos serviços em questão depende diretamente da execução por um profissional habilitado (Freidson, 1998). Considerando a trajetória histórica e as protoformas do Serviço Social no Brasil, o público para o qual se destina o seu trabalho e, principalmente, as vinculações históricas entre religião, caridade e voluntarismo na prestação de serviços de assistência social (Iamamoto e Carvalho, 2009), não parece uma tarefa fácil conquistar o apoio de importantes setores para o reconhecimento legal da profissionalização dos serviços que até então eram prestados quase que exclusivamente por instituições e obras de caridade.

Sobre esse assunto, destaca-se novamente a visão impressa em importantes trechos dos relatórios e justificativas dos legisladores que vinculam, quando não reduzem, o Serviço Social à assistência social. Nessa linha, registra-se que a assistência social só foi reconhecida como política pública de Seguridade Social em 1988, apenas um ano antes da apresentação do Projeto n. 3.903 de 1989. Mesmo com essa conquista, muitos anos se passaram até que a Política de Assistência Social (2004) conquistasse diretrizes, tipificações, normatizações e equipamentos que materializassem sua organização como direito, e não como favor, consequentemente sujeita ao campo do amadorismo. 
Quanto ao registro das entidades e demais pessoas jurídicas referidas no artigo 16 do projeto, cabe destacar a incongruência do legislador se comparadas à legislação do Serviço Social com a de outras profissões. Diversas profissões brasileiras possuem em sua regulamentação artigos que condicionam a inscrição e o pagamento de taxas e anuidades por parte das pessoas jurídicas aos conselhos profissionais, além de obrigar a presença de profissionais habilitados. Sobre esse assunto, são exemplos a Medicina Veterinária, fundamentada na Lei $n^{\circ} 5.517$ de 1968, a Engenharia e a Arquitetura (Lei n ${ }^{\circ} 5.194$ de 1966) e a Odontologia, cuja regulamentação (Lei no 4.324) data de 1964. Outros exemplos são a Nutrição e a Educação Física, as quais também registram tais instituições em seus quadros, bem como cobram taxas das empresas que prestam serviços vinculados às respectivas profissões em ambos os casos, os conselhos de fiscalização estão amparados pela Lei $n^{0} 6.839$ de 1980, que também deveria abranger o Serviço Social.

O legislador, porém, negando a legislação já vigente à época, retira o artigo 16 do projeto de lei do Serviço Social com base na seguinte fundamentação:

O artigo 16, por outro lado, faz compulsória a inscrição das referidas entidades nos conselhos regionais, sujeitando-as, assim, ao pagamento das contribuições, taxas e emolumentos.

Ora, se considerarmos o tipo de atividade desempenhada por tais entidades (assistência social), o que as torna permanentemente carentes de recursos, como compeli-las ao enfrentamento de mais um ônus, de cunho cartorial, burocrático e sem qualquer vinculação direta com seus objetivos verdadeiros? (Brasil, 1992b, p. 27.789)

Dessa maneira, a exclusão de mais esse artigo fez diminuir o poder de fiscalização dos CRESS e do CFESS em relação ao controle e à garantia das condições de trabalho, além da obrigatoriedade de assistentes sociais em determinadas empresas e entidades. As possibilidades de penalidades (inclusive multas) aplicáveis pelos conselhos às pessoas jurídicas ficaram reduzidas às situações em que se provem participação ou conivência das 
mesmas nas infrações cometidas por profissionais, conforme artigo 16 da atual Lei ${ }^{\circ} 8.662 / 93$.

Por último, foram incluídos os agentes sociais previstos na antiga Lei $\mathrm{n}^{\mathrm{o}} 1.889 / 53$ como indivíduos que poderão exercer a profissão de assistente social. Tal fato havia sido negligenciado no projeto apresentado em 1989. Posteriormente, o projeto substitutivo foi encaminhado para apreciação de novas comissões parlamentares, as quais mantiveram todas as alterações sem nenhum recurso apresentado, nem mesmo pelas autoras do projeto original. O projeto seguiu para a sanção presidencial.

Antes de ser sancionado em 7 de junho de 1993, o projeto ainda sofreu três vetos presidenciais (Brasil, 1993). O primeiro, realizado no artigo $4^{\circ}$, inciso IV, retirou a competência prevista ao assistente social de ocupar cargos efetivos e de comissão, funções de assessoria, direção, supervisão, chefia e execução em entidades prestadoras de Serviço Social. A justificativa se baseou em dois fatos: 1 - para ocupar os aludidos postos, os profissionais teriam que ser aprovados em concurso público ou ser nomeados por confiança; 2 - A ocupação dos cargos está condicionada à natureza da atividade, e não da instituição, pois o simples fato de a instituição ser prestadora de serviço social não indica que todos os seus membros exerçam tarefas de assistente social.

O segundo veto se deu no inciso IX do artigo $8^{\circ}$. O texto previa a mesma função de disciplinar, fiscalizar e normatizar atividades de pessoas jurídicas cujas ações estejam ligadas ao Serviço Social retirada durante o processo legislativo. O trecho idêntico foi excluído pelo Senado no que se referia aos CRESS, mas havia permanecido no artigo que trata das competências do CFESS.

Já o último veto promoveu a exclusão completa do artigo $21^{\circ}$. Ele previa aos membros do conjunto CFESS/CRESS liberação integral dos empregados públicos ou privados para a ocupação de mandatos nas entidades de categoria. O presidente entendeu que: essa ação já estava regulamentada na Lei no 8.112 de 1990 no que tange aos servidores públicos; uma mudança na carreira pública federal só poderia ser feita por projeto de iniciativa da Presidência da República (dada previsão constitucional); quanto aos empregados das 
empresas privadas, várias tentativas parecidas já haviam sido impedidas pelo próprio Congresso Nacional.

\section{Considerações finais}

Após cerca de quatro anos, com todas essas importantes mudanças, entrou em vigor a nova Lei de Regulamentação do Serviço Social - 8.662 de 1993. Como se buscou demonstrar, o projeto que culminou na atual legislação passou por alterações que contribuíram significativamente para a indefinição nas atribuições inerentes a essa especialização do trabalho na relação em outras profissões, algumas já identificadas por Terra (1998) e Iamamoto (2012).

Nessa perspectiva, reduzindo as possibilidades de estabelecer as fronteiras que marcam as tarefas privativas da profissão, seja pela manutenção de termos como área, unidade e matéria de Serviço Social sem definição, seja pela exclusão ou mudança de incisos, a legislação acaba deixando em aberto, para a execução por outras ocupações ou mesmo leigos, uma gama de atividades que historicamente têm sido identificadas como monopólios do assistente social, tais como: o estudo socioeconômico para inclusão em benefícios; a emissão de pareceres sociais; o acompanhamento e a orientação social de indivíduos e famílias inseridos em serviços e programas sociais.

Essas questões colocam em evidência a necessidade de mais estudos e pesquisas que tomem como objeto as relações profissionais entre o Serviço Social e as demais ocupações, identificando e refletindo sobre suas competências e, principalmente, suas atribuições privativas. Além disso, ao CFESS, assim como fazem os demais conselhos de categoria, reforça-se a necessidade de se problematizar e normatizar, por meio de resoluções, certas tarefas e atribuições já realizadas pelo Serviço Social, mas ainda pouco definidas na legislação federal.

Recebido em 21/2/2017 - Aprovado em 23/10/2017 


\section{Referências bibliográficas}

ALMEIDA, D. A efetivação das competências e atribuições legais na atividade profissional dos assistentes sociais da Secretaria Municipal de Assistência Social da prefeitura de Londrina - PR. Dissertação (Mestrado em Serviço Social) - UEL, Londrina, 2006.

BRASIL. Lei no 3.252 de 27 de agosto de 1957. Regulamenta o exercício da profissão de assistente social. Disponível em: $<$ http://www.planalto.gov.br/ccivil_03/bleis/L3252. htm>. Acesso em: 9 fev. 2017.

. Decreto $\mathrm{n}^{\mathrm{o}} 994$ de 15 de maio de 1962. Regulamenta a Lei $\mathrm{n}^{\mathrm{o}} 3.252$, de 27 de agosto de 1957, que dispõe sobre o exercício da profissão de Assistente Social. Disponível em: <http://www2.camara.leg.br/legin/fed/decmin/1960-1969/ decretodoconselhodeministros-994-15-maio-1962-351749-publicacaooriginal-1-pe. html>. Acesso em: 18 dez. 2017.

. Lei $\mathrm{n}^{\circ} 4.324$ de 14 de abril 1964. Institui o Conselho Federal e os Conselhos Regionais de Odontologia, e dá outras providências. Disponível em: <http://www.cfo. org.br/wpcontent/ uploads/2009/09/lei4324.pdf>. Acesso em: 9 fev. 2017.

. Decreto $n^{\circ} 53.464$ de 21 de janeiro de 1964. Regulamenta a Lei n ${ }^{\circ} 4.119$, de 27 de agosto de 1962, que dispõe sobre a profissão de psicólogo. Disponível em: $<$ http://www. crprj.org.br/legislacao/documentos/decreto1964-53464.pdf>. Acesso em: 9 fev. 2017.

. Lei $\mathrm{n}^{\circ} 5.517$ de 23 de outubro de 1968. Dispõe sobre o exercício da profissão de médico-veterinário e cria os Conselhos Federal e Regionais de Medicina Veterinária. Disponível em: <http://www.planalto.gov.br/ccivil_03/ leis/L5517.htm>. Acesso em: 9 fev. 2017.

. Lei $\mathrm{n}^{\circ} 6.839$ de 30 de outubro de 1980. Dispõe sobre o registro de empresas nas entidades fiscalizadoras do exercício de profissões. Disponível em: $<$ http://www. planalto.gov.br/ccivil_03/leis/L6839.htm>. Acesso em: 9 fev. 2017.

. Constituição da República Federativa do Brasil de 1988. Disponível em: $<$ http://www.planalto.gov.br/ccivil_03/constituicao/constituicao.htm>. Acesso em: 9 fev. 2017.

. Congresso. Diário Oficial do Congresso Nacional. Brasília, DF, 31 de out. de 1989. Seção I, p. 12.691-12.693. 
BRASIL. Congresso. Diário Oficial do Congresso Nacional. Brasília, DF, 5 de dez. de 1990. Seção I, p. 13.335-13.343.

. Congresso. Diário Oficial do Congresso Nacional. Brasília, DF, 11 de mar. de 1992a. Seção I, p. 3407-3412.

. Congresso. Diário Oficial do Congresso Nacional. Brasília, DF, 29 de dez. de 1992b. Seção I, p. 27.284-27.790.

. Lei n ${ }^{\circ} 8.662$ de 7 de junho de 1993. Dispõe sobre a profissão de assistente social e dá outras providências. Disponível em: <http://www.planalto.gov.br/ccivil_03/ leis/L8662.htm>. Acesso em: 9 fev. 2017.

CFESS. Atribuições privativas do assistente social em questão. Brasília: CFESS, 2012.

COELHO, E. C. As profissões imperiais: medicina, engenharia e advocacia no Rio de Janeiro 1822-1930. Rio de Janeiro: Record, 1998.

DINIZ, M. Os donos do saber: profissões e monopólios profissionais. Rio de Janeiro: Revan, 2001.

FELIPPE, J. Projetos profissionais do Serviço Social e da Psicologia nos CRAS: uma articulação bem-sucedida? Vértices, Campos dos Goytacazes, v.15, n. 1, p. 97-111, 2013. . Atribuições privativas do Serviço Social sob um novo enfoque analítico. Dissertação (Mestrado em Serviço Social) — UERJ, Rio de Janeiro, 2014.

FERREIRA, A. Novo Aurélio século XXI: o dicionário da língua portuguesa. Rio de Janeiro: Nova Fronteira, 1999.

FREIDSON, E. Renascimento do profissionalismo: teoria, profecia e política. São Paulo: Edusp, 1998.

IAMAMOTO, M. Projeto Profissional, espaços ocupacionais e trabalho do(a) assistente social na atualidade. In: CFESS. Atribuições privativas do assistente social em questão. Brasília: CFESS, 2012.

; CARVALHO, R. Relações sociais e Serviço Social no Brasil: esboço de uma interpretação histórico-sociológica. São Paulo: Cortez/Celats, 2009.

LARSON, M. S. The sise of professionalism: a Sociologial Analysis. Los Angeles: University of Califórnia Press, 1977. 
PESSANHA, M. F. A sistematização do trabalho dos assistentes sociais que atuam na Assistência Social/Cras no município de Campos dos Goytacazes: uma análise de sua contribuição para a afirmação. Monografia (especialização em Serviço Social, direitos sociais e competências profissionais) — Brasília: UnB, 2010.

SIMÕES, C. Na ilha de Robinson: a autonomia e a ética profissional no neoliberalismo. Serviço Social \& Sociedade, São Paulo, n. 99, p. 405-424, 2009.

TERRA, S. Parecer jurídico $n^{\circ}$ 27/98. Brasília: CFESS, 1998.

TORRES, M. Atribuições privativas presentes no exercício profissional do assistente social: uma contribuição para o debate. Libertas, Juiz de Fora, v. 1, n. 2, p. 42-69, 2007. 